after the clinic had lost its novelty. No infant was ever compelled to conform to any dietetic dogma by Professor Budin. He studied the feeding of each new patient as a fresh problem. I can confidently assert that none "were wrecked before the end of thirty days" from exposure to "an ordeal of undiluted sterilised milk," and if your reviewer wishes I shall gladly obtain for him the details of every case which attended Professor Budin's consultations for less than one montl.

Thanking you for this opportunity to correct a false impression for which, perhaps, I am somewhat to blame, I am, Sirs, yours faithfully, W. J. MaLONeY. M.B. Edin.

Brook-street, Grosvenor-square, W., March 12th, 1907.

\section{AN OPEN-AIR SCHOOL.}

\section{To the Editors of THE LANCET.}

SrRs,-In the article by Mr. C. H. Garland and Dr. T. D. Lister on a National School for Consumptives we are told of the necessity for education in hygiene. ${ }^{1}$ The education is to be confined, however, to the working class and to those suffering from tuberculosis. Should not a National School of Hygiene take into consideration a method of living which would prevent the commencement of disease? and is not the wellto do class equally in need of instruction as to the duty and methods of healthy living? It is with the idea of forwarding such an education that I am erecting in Garden City the building which $I$ am calling an open-air school. It is an attempt to demonstrate the possibility of truly healthy conditions of living, not for invalids but for perfectly healthy persons, the result aimed at being to teach the possibility of preventing the first awakening of the germs of consumption.

This life is not to be (as was suggested in the article) "soft" more than any other life lived in the world. Openair sleeping, eating, and bathing are to be combined with absolutely normal activities. It is proposed by rational feeding and reasonable intellectual and artistic development to produce a finer type of physique and a higher degree of mental and moral capacity than is at present known. I should gladly welcome any inquiry or any visit, though the building will not be complete for several months.

March 18th, 1907. I am, Sirs, yours faithfully,

A. J. LAWRENCE.

\section{GRADUATED LABOUR IN SANATORIUMS.}

\section{To the Editors of TeE LANCET.}

SIRS, - Your readers may be interested to know that the system of graduated labour advocated by $\mathrm{Mr}$. C. H. Garland and Dr. T. D. Lister in your issue of March 9th for patients in sanatoriums has been in force for two years in this institution with satisfactory results. I have had the pleasure of demonstrating this system both to Mr. Garland and Dr. Lister, and am glad to find they now advocate its general adoption. Agair, the suggestion of these gentlemen that patients should be taught to take an intelligent interest in their treatment, and that the cause of the disease and methods of its prevention and arrest should be explained fully to each individual has been adopted here since the institution was opened. We have found, however, that "talks in the recreation room," when combined with close supervision of individual patients and continuous coöperation between doctors and patients, yield far more satisfactory results than any pamphlets or other literature, and in my experience amongst the working classes short individual conversations will do more good in a day than teaching by pamphlet will do in a month.

There is one paragraph in the article which appears to me to be original. I refer to the statement that " it is generally humiliating to a man to perform domestic duties like bed-making, floor-scrubbing, washing-up, and similar duties." An ounce of practice is worth a ton of theory. In our experience here we have never met this feeling of humiliation. Our male patients, when well enough to do so, make their own beds and keep their wards and crockery clean. They do this work cheerfully and well. The men of our navy, army, and mercantile marine, and men in other occupations daily perform such work as "bed-making,

1 THE LANCET, March 9th, 1907, p. 677 floor-scrubbing, and washing-up." Are all these men suffering from a sense of humiliation?

I am, Sirs, yours faithfully,

M. S. Paterson.

Brompton Hospital Sanatorium, Frimley, March 11th, 1907.

\section{TREATMENT OF DISTENSION OF THE INTESTINES.}

To the Editors of THE LANCET.

Sirs,-The treatment of distension of the intestines, whether following operation or otherwise, is always a matter of difficulty. There has been a considerable amount of correspondence upon the subject in your columns from time to time showing that the question is of importance. My object in writing is to protest against the treatment by puncture. I imagined that such a procedure was relegated to the past and that a student who suggested it at his examination would be sent down for six months. To my surprise I find that this is not so and I have just read in a clinical lecture by a physician at one of the leading London hospitals: "The prognosis of acute gastric dilatation is, however, much better than that of tympanites, for while it is easy to evacuate a distended stomach by the tube it is very difficult to deal mechanically with distension of the intestines. The distended coils of intestine may, it is true, be punctured ' nith impunity' (italics are mine!) by a trocar and cannula, but the escape of gas by the cannula is barely sufficient to give permanent relief."

If this is the teaching which students receive it is not surprising that they should act in accordance with it. That they do is supported by the fact that I was recently called upon to operate on a case of septic peritonitis due to this cause. 'This, 1 think, is sufficient evidence to justify me in drawing attention to the subject.

I am, Sirs, yours faithfully,

T. LTONEL STRETTON,

March 15th, 1907. Senior Surgeon, Kidnerminster Infiren's Hospita'.

\section{ON THE CONDITION OF THE BLOOD- VESSELS DURING SHOCK.}

To the Elitors of THE LANCET.

SIRs,--Though firmly persuaded of the truth of Mark Pattison's saying that "of all the ways of wasting time controversy is the most unprofitable," I feel that I must beg space to reply to Mr. J. D. Malc slm's letter on this subject which appears in your issue of March 16 th.

In any sphere of thought it is rare; in medicine it is conspicuously rare, for a theory to be found which will at once embrace all the facts. In the present state of our knowledge we have often to decide between two explana. tions which are diametrically opposed to one another, and in making our selection between them we have nothing to aid us except the weight of available evidence. Even where the preponderance of that evidence is overwhelmingly on one side, there are not infrequently irritating little facts which, for a time at any rate, decline to be included in the fold It is facts of this nature upon which, in his tilt against the accepted explanation of the phenomena of shock, Mr. Malcolm has seemed to me unduly to dwell, to the exclusion of those matters of real import upon which the accepted explanation is based. If he wishes to persuade us not only that this explanation is wrong, but that it represents the exact opposite of the true one instead, of insisting upon differences in detail between two observers who are in com. plete consonance on the main question, Mr. Malcolm ought surely to begin by showing that there are fallacies in the arguments by which the $\mathrm{Cr}$ ssent view is supported. Of these arguments I select one for his demolition. It is possibly not the most cogent of the many which might be adduced; it has, at any rate, the merit of simplicity. It is this. The sphygmanometer shows that the blood pressure in shock is invariably subnormal. ' The state of the blood pressure depends upon $(a)$ the heart, and $(b)$ the arteries. Mr. Malcolm has expressed himself satisfied ${ }^{2}$ that the heart is not affected in shock. There remain therefore the arteries, including, of course, the arterioles. When these

1 The Clinical Study of Blood Pressure, T. C. Janeway, 1904, p. 273. 2 THE LANCET, March 16th, 1907, p. 762. 